\title{
Inovação em educação na berlinda: da instrumentalização à emancipação
}

\author{
Darlan Marcelo Delgado \\ Centro Estadual de Educação Tecnológica Paula Souza - São Paulo
}

\section{Resumo}

0 artigo tem como escopo a inovação em educação, particularmente na área de política e gestão educacional. Aborda-se a inovação e suas relações com o setor produtivo e com a política de ciência e tecnologia no contexto em que aquela é crescentemente valorizada como fator gerador de vantagens competitivas para o mercado. 0 objetivo central da pesquisa é diferenciar duas tipologias polarizadas de inovação em educação, derivadas de concepções educacionais antagônicas - a economicista e a emancipatória -, para, então, esboçar a trajetória à elaboração da acepção de inovação educacional críticoemancipatória, oriunda das contribuições teóricas dos autores da Teoria Crítica.

Palavras-chave: Política e gestão educacional. Política de CT\&I. Inovação em educação. Teoria Crítica. 


\section{Innovation in education on the spot: from instrumentation to emancipation}

This article shows as its scope the innovation in education, particularly in the field of political and educational management. It approaches innovation and its relation to the productive sector and the Science and Technology policy, in the context in which it is increasingly valued as a competitive generator of advantages for the market. The main purpose of this research is to distinguish two polarized typologies of innovation in education derived from antagonistic educational conceptions, the economistic and the emancipatory, and then, sketch the path to the elaboration of a criticalemancipatory educational innovation acceptation, deriving from the contributions of the Critical Theory.

Keywords: Politics and educational management. CT\&I Policy. Innovation in education. Critical Theory.

\section{Innovación en la educación en foco: de la instrumentalización a la emancipación}

Este artículo tiene por objeto la innovación en la educación, en particular en el ámbito de la política y la gestión educacional. Se aborda la innovación y sus relaciones con el sector productivo y con la política de ciencia y tecnología en el contexto en que esta está crecientemente valorada como un factor generador de ventajas competitivas para el mercado. El objetivo central de la investigación es diferenciar dos tipologías polarizadas de innovación en educación derivadas de concepciones antagónicas, la economicista y la emancipadora, y así, esbozar la trayectoria a la elaboración de la acepción de la innovación educacional crítico-emancipadora, procedente de las contribuciones de la Teoría Crítica.

Palabras-clave: Política y gestión educacional. Política de CT\&I. Innovación en educación. Teoría Crítica. 


\section{Introdução}

0 presente ensaio aborda o tema da inovação, não apenas como marca emblemática do atual estágio do capitalismo - ou seja, de economia globalizada (desregulamentada e financeirizada), do setor produtivo atravessado pelas transformações do pós-fordismo (sistema flexível de produção), de concorrência crescentemente acirrada e predatória pautada pelo ditame do ritmo acelerado do progresso da tecnologia microeletrônica de base digital, da biotecnologia e das tecnologias da informação e comunicação (TICs) -, mas também como fenômeno que migrou para o campo da formação humana e do conhecimento, tendo-se lá instalado. Nesse cenário, tanto a política de ciência e tecnologia (PCT) quanto a política educacional se encontram pressionadas por discursos exigentes de inovação oriundos do setor produtivo.

Os urgentes pedidos por inovações e "choques de gestão" que proporcionem mudanças no sentido de gerarem vantagens competitivas ecoam em diversas instâncias (e instituições sociais), incluindo a academia e a própria escola, como local onde se formam os futuros egressos que irão compor nesta sociedade, a um só tempo, consumidores e trabalhadores. A lógica é a da competitividade baseada em conhecimentos técnico-científicos de natureza aplicada, busca pela crescente produtividade do trabalho e do capital e maximização da lucratividade empresarial. Cada uma a seu modo e nos seus espaços tradicionais, ciência e educação são convocadas a renderem louvores ao utilitarismo econômico. Percebe-se, assim, uma marcante tendência de a razão instrumental advinda do mercado conduzir - no sentido de subordinar e condicionar - as políticas de C\&T e de educação, implicando que as necessidades inerentes à política industrial e às ações das políticas de inovação empresarial em geral pressionariam as duas primeiras esferas de política pública. De acordo com Dias (2011), é notável a dinâmica de aumento da influência da economia da inovação nas reflexões sobre a PCT. Verifica-se um embate de diferentes concepções de desenvolvimento econômico em disputa, lado a lado com não menos antagônicas concepções de ciência e de educação e seus fins.

Nesse contexto, o "progresso técnico" via inovação foi alçado a fator crítico para o sucesso empresarial brasileiro diante da competição internacional. Isso se verifica marcadamente após o governo Sarney, quando há o início do processo de abertura econômica. É nesse período histórico recente que a inovação recebeu o status de indutora do desenvolvimento econômico sustentável (CNI, 2005) e o discurso que the dá aporte passou a legitimar enfaticamente uma concepção utilitarista de ciência e de educação.

0 escopo deste estudo localiza-se no embate de concepções de inovação em 
educação, a partir do qual pretendo esboçar uma noção de inovação educacional crítico-emancipatória fundada nos pilares teóricos herdados dos autores da primeira geração da Teoria Crítica, em particular de Theodor Adorno. Para tanto, na primeira seção abordo a relação entre inovação, ciência e tecnologia no Brasil do período da transição democrática da década de 1980, em termos dos requisitos econômicos e de mercado de um país recentemente aberto à competitividade internacional. Ainda nesta seção, tento demonstrar como o Ministério da Ciência e Tecnologia incorporou o discurso desenvolvimentista, assim como também se teria colocado sobre os ombros da educação básica a responsabilidade de formar os egressos considerados "ideais" para o novo cenário de competitividade, assentado nos frutos da ciência aplicada. Na segunda seção, traço um panorama das abordagens teóricas sobre a inovação em educação e posteriormente destaco a polarização entre duas concepções de inovação educacional a partir da obra de Veiga (2003). É a partir da compreensão crítica da noção de inovação regulatória ou técnica que reúno os elementos necessários para, na quarta seção, apresentar as condições que comporiam a essência de uma abordagem de inovação críticoemancipatória alicerçada nas contribuições de Adorno. Por fim, teço algumas considerações a título de compor um breve balanço das discussões apresentadas.

\section{Inovação, ciência e a arena da política educacional}

O vínculo entre educação e ciência no início do período de redemocratização do País pode ser compreendido mediante a abordagem de Shozo Motoyama em artigo do primeiro número da Revista da Sociedade Brasileira de História da Ciência. 0 texto é a exposição do autor, em novembro de 1984, durante o “Seminário ciência, tecnologia e desenvolvimento", promovido pela Comissão de Ciência e Tecnologia da Câmara dos Deputados (Motoyama, 1985). Objetivava-se, naquela oportunidade, traçar as linhas mestras em ciência e tecnologia (C\&T) do futuro governo a ser empossado no País, em março de 1985, o qual apresentava graves problemas sociais, vivenciava aguda crise econômica, convivendo com altas taxas de inflação, e registrava indicadores educacionais - especialmente de analfabetismo e de taxas de escolarização da população ${ }^{1}$ - desanimadores, caracterizando a persistência de uma escola excludente. (Cunha, 2012)

1. Do total da população com idade superior a 15 anos, $20,7 \%$ eram analfabetos. Na região Nordeste, esse índice alcançava $39,7 \%$ da população. Apenas $15,3 \%$ da população brasileira de 15 a 19 anos possuíam o ensino de $2 .^{\circ} \mathrm{grau}$ (atual ensino médio) no ano de 1985. (Cunha, 2012) 
Motoyama (1985) apresenta o caráter pragmático-imediatista das escassas e pontuais ações da política de ciência e tecnologia conduzidas até então e aponta para o descaso nacional com a formação educacional e, assim, com a capacitação técnica (formação de recursos humanos) para as diversas exigências e demandas da sociedade, particularmente do setor produtivo. Se no final do século XIX, nos países centrais, as necessidades na saúde, na agricultura, na engenharia e outras impulsionaram a busca por saberes técnicocientíficos que delas pudessem dar conta, a tradição e a cultura brasileiras engessavam o País ao simples papel de importador de tecnologias. Segundo o autor, a metáfora adequada à ciência - e porque não à própria educação? - era a de "ornamento dispensável", dado que C\&T nunca foram prioridades reais das políticas do País.

Se de um lado a ciência foi quase sempre encarada como "ornamento" capaz de minorar as "misérias culturais brasileiras", de outro a técnica fora le aparentemente ainda él endeusada como ente mirífico "capaz de despedaçar os entraves do subdesenvolvimento" (Motoyama, 1985). Tendo-se esse panorama, - autor encaminhou algumas propostas para as políticas de C\&T. Entre elas estavam a criação do Ministério da Ciência e Tecnologia (MCT), destinação de recursos financeiros à ciência atrelados a percentuais fixos do Produto Nacional Bruto (PNB) e a valorização da educação em todos os níveis, tornando a profissão do educador mais atraente, em particular a educação científica desde o ensino de $1 .^{\circ}$ grau latual ensino fundamental).

Passados trinta anos, verifica-se que o MCT, criado em 1985, no governo de José Sarney, foi recentemente renomeado, passando a incorporar a "inovação" em seu nome oficial - Ministério da Ciência, Tecnologia e Inovação (MCTI)² -, expressando o quanto a inovação assumiu caráter balizador da política nacional de C\&T, orientada intensamente pelas necessidades oriundas da atual concorrência capitalista, assentada em produtos e processos inovadores. Isso se dá pelo fato de a ciência estar se tornando cada vez mais tecnológica e a técnica, por seu turno, cada vez mais científica, conforme argumenta Dias (2011). A partir de análise histórica das relações entre progresso tecnológico e ciência, Rosenberg 12006 , p. 240) assevera que "[a] ciência vem sendo moldada, direcionada e constrangida por poderosos estímulos econômicos". Por seu turno, a educação é pressionada inevitavelmente a também inovar, nas políticas educacionais assim como nas ações e práticas de gestão educacional, condicionadas que se encontram pelo discurso de adaptação à mudança perene imposta por tal racionalidade advinda

2. O Ministério da Ciência e Tecnologia (MCT) teve seu nome alterado, passando a incorporar o termo "inovação" a partir de 03 de agosto de 2011. (publicação no Diário Oficial da União) 
do setor produtivo e do mercado. A inovação se torna um modismo, algo colocado como indispensável em todas as dimensões da vida social humana. Inovar é uma lógica sistêmica, ou seja, em relação com o sistema do capital e, portanto, com o mercado, que segundo Türcke (2010, p. 34) deixa de ser mera instância ou instituição social na qual ocorre a troca de bens econômicos la relação contratual entre agentes ditos livres) e se torna "instância central de socialização".

Verifica-se, assim, uma acelerada ascensão do valor conferido à inovação na contemporaneidade. Os consumidores são educados pela indústria cultural a se renderem ao poder de sedução das inovações embarcadas nos mais diversos produtos, nessa "sociedade da sensação", expressão empregada por Christoph Türcke para expressar o fenômeno da inaudita pressão exercida pela indústria cultural da era digital, da economia globalizada orientada pelas concepções do neoliberalismo sobre toda a sociedade. A argumentação do autor está assentada na percepção de que tudo que não for capaz de "causar uma sensação tende a desaparecer sob o fluxo de informações, praticamente não sendo mais percebido, então isso quer dizer, inversamente, que o rumo vai na direção de que apenas o que causa uma sensação é percebido". (Türcke, 2010, p. 20)

Esse movimento de valorização da inovação migra do mercado para o campo do conhecimento, o que pode ser verificado observando-se algumas ações do Ministério da CT\&l, que elegeu 2002 o "ano da inovação". Quando se realizou a 4. ${ }^{a}$ Conferência Nacional de Ciência, Tecnologia \& Inovação (CNCT\&I), em 2010, a educação básica estava entre os temas integrantes da agenda de debates, merecendo uma sessão plenária intitulada “Educação e C,T\&l: educação de qualidade desde a primeira infância" (Brasil, 2010a; 2010b). Resultou dessa conferência a noção sobre a necessidade de uma "revolução" desde a educação básica até o ensino superior, defendida devido aos hiatos existentes entre os indicadores educacionais do Brasil e de outros países, particularmente os países da Organização para a Cooperação e Desenvolvimento Econômico (OCDE), os tigres asiáticos e outros emergentes. 0 ensino médio recebeu atenção especial, dado seu caráter estratégico de terminalidade da educação básica e etapa que forma egressos para o mundo do trabalho, para prosseguimento de estudos na educação superior ou na educação profissional.

Alguns exemplos de inovações podem ser encontrados na política educacional com impacto no ensino médio, como a emenda constitucional n. ${ }^{0} 59$, de 2009 , que alterou o inciso I do art. 208 da Constituição Federal, passando o Estado a garantir a educação básica como obrigatória e gratuita dos 4 aos 17 anos de idade, a propositura do "Programa Ensino Médio Inovador - ProEMI" (Brasil, 2009), e, como terceira inovação, a Resolução CNE/CEB n. ${ }^{0}$ 2/2012 (Brasil, 2012a), derivada do Parecer CNE/CEB n. ${ }^{\circ}$ 5/2011 (Brasil, 2012b), que define as novas Diretrizes 
Curriculares Nacionais para o Ensino Médio (DCNEM), revogando a Resolução CNE/CEB n. ${ }^{\circ}$ 3/1998. As novas DCNEM reforçam a indissociabilidade entre teoria e prática e trazem a relação articulada entre trabalho, tecnologia, ciência e cultura. Contudo, a visão funcionalista da educação como instrumento renovador eficaz da sociedade e, portanto, que vincula formação educacional e progresso econômico (algo típico do liberalismo econômico e do tecnicismo pedagógico), fica evidente no Parecer CNE/CEB n. ${ }^{0}$ 5/2011:

Para alcançar o pleno desenvolvimento, o Brasil precisa investir fortemente na ampliação de sua capacidade tecnológica e na formação de profissionais de nível médio e superior. Hoje, vários setores industriais e de serviços não expandem na intensidade e ritmos adequados ao novo papel que o Brasil desempenha no cenário mundial, por se ressentirem da falta desses profissionais. Sem uma sólida expansão do Ensino Médio com qualidade, por outro lado, não se conseguirá que nossas universidades e centros tecnológicos atinjam o grau de excelência necessário para que o País dê o grande salto para o futuro. (Brasil, 2012b, p. 1)

Percebe-se que uma inadequada ou insuficiente ação da política educacional dedicada ao ensino médio poderia causar constrangimentos ao desenvolvimento do País no que concerne ao papel de "qualificação" profissional. Os pareceristas não se limitam, entretanto, a abordar apenas o caráter economicista desse nível educacional, pois ponderam que a educação esperada ultrapassa a dimensão da formação profissional, alcançando as questões relativas à construção da cidadania, da autonomia intelectual e assegurando o conhecimento historicamente acumulado, constituindo-se em ponto nodal de onde frutificam os saberes para ativar o exercício dos demais direitos sociais. (Brasil, 2012b)

Os princípios "educativo", "pedagógico" e "norteador", respectivamente, o trabalho, a pesquisa e os direitos humanos, além da sustentabilidade ambiental como “meta universal”, são apresentados no artigo 13 da resolução, o qual assegura que as unidades escolares "devem" orientar a definição de toda proposição curricular, fundamentada na seleção dos conhecimentos, componentes, metodologias, tempos, espaços, arranjos alternativos e formas de avaliação tendo presente cada um desses princípios, além de enfatizar as dimensões do trabalho, da ciência, da tecnologia e da cultura como eixos integradores entre o conhecimento de distintas naturezas, o que deverá ser feito no currículo e na proposta pedagógica (projeto político-pedagógicol contextualizando-os em sua dimensão histórica e em relação à realidade social.

Cumpre destacar dois aspectos inerentes a esta resolução e a seu parecer. 0 primeiro refere-se à relevância conferida à ciência e à técnica nas novas DCNEM, 
em que fica implícita uma noção de alfabetização científica ${ }^{3}$ no ensino médio, dada a decisão de se promover a pesquisa como princípio pedagógico e de se colocar a iniciação científica como componente da atividade curricular desejável nesse nível de ensino. 0 segundo aspecto é a tensão presente entre uma visão instrumental - do discurso que busca legitimar o ensino médio como etapa estratégica para cumprir a função social de geração de egressos com a formação considerada ideal pelo mercado - e uma visão humanista ampla, orientada à plena formação do indivíduo para a vida social, envolvendo as dimensões do exercício da cidadania para a consolidação de uma sociedade plural e democrática.

Essa orientação mais deslocada em direção à alfabetização científica na construção da proposta curricular exigiria inovações na construção do projeto político-pedagógico. Isso, por sua vez, implica a estreita articulação entre a inovação da política e as inovações necessárias na gestão educacional. 0 desafio, em termos de uma orientação teórico-metodológica inspirada nas contribuições de Theodor Adorno, estaria posto exatamente neste ponto: a tomada de posição política e a ação de gestão por parte dos profissionais da educação na construção dos projetos pedagógicos deveriam ser de tal modo elaboradas a não se encontrarem meramente subordinadas à racionalidade instrumental, pois daí resultaria uma concepção de educação voltada à adaptação do indivíduo ao sistema social (e ao mercado), à heteronomia e a uma questionável formação para o trabalho. Essa tomada de posição a parir de Adorno requer pensar a política educacional e elaborar as ações de gestão pautadas pela concepção norteadora de uma educação crítica e emancipatória, orientada à autorreflexão, portanto, à formação da consciência do indivíduo e mirando a sua liberdade de pensar a realidade e nela agir, tendo-se ciente o enfrentamento da mesma realidade dada objetivamente, marcada pela semiformação. É devido a esse complexo desafio e sua contextualização no que se refere às demandas de inovação em sentido amplo e na esfera da educação que passo, na próxima seção, a apresentar as abordagens sobre inovação em educação.

\section{Inovação em educação: crítica da “inovação regulatória ou técnica”}

No início dos anos 1970, foi traduzida e publicada no Brasil a obra de Alan Huberman (1973). A partir de uma matriz teórica assentada na psicologia comportamental e de uma visão sistêmica da organização escolar, as inovações

3. No parecer se coloca que a pesquisa como princípio pedagógico propiciaria o desenvolvimento da "atitude científica". (Brasil, 2012b, p. 22) 
eram tomadas como algo novo enxertado no velho a partir de fora e, portanto, de modo imposto hierarquicamente. Ele elaborou uma definição de inovação muito semelhante ao conceito de função de produção da teoria da firma da corrente neoclássica da ciência econômica: “a inovação nos conduz, no domínio da tecnologia social, à descoberta da combinação mais eficaz de meios visando a alcançar fins específicos" (Huberman, 1973, p. 16). É marcante o caráter teleológico de tal definição, antecipando seu emprego normativo e, portanto, prescritivo das operações de implantação de inovações educacionais tanto na elaboração de políticas educacionais quanto nas próprias formas e meios de gestão necessários para executar as ações que garantissem a eficiência (econômical dos recursos (humanos e materiais) para alcançar os objetivos propostos, obtendo-se assim a pretendida eficácia.

Sua definição de inovação é a de "uma operação completa em si mesma cujo objetivo é fazer instalar, aceitar e utilizar determinada mudança" (Huberman, 1793, p. 17). Como se vê, o autor coloca em campos distintos o planejador e o executor, visto como mero "assimilador" da inovação, revelando a típica hierarquia gerencial da escola clássica da administração, de inspiração taylorista.

Também ao abordar a inovação no campo da educação, a mesoabordagem do pesquisador luso António Nóvoa revela-se como um dos aportes teóricometodológicos desembarcados no Brasil, já nos anos 1990. Segundo Nóvoa (1992), os estudos até então conduzidos sobre a educação e suas inovações e mudanças se concentravam no nível macro dos sistemas educacionais ou no nível micro da sala de aula. Sendo assim, argumenta que produzir uma inovação era sinônimo de conceber e implantar algum tipo de reforma estrutural no sistema educativo lou a partir dele; uma inovação imposta verticalmente, como em Huberman) ou, por outro lado, a inovação era entendida como a aplicação de novos métodos e técnicas pedagógicas na sala de aula. Conforme explica o autor,

Hoje, parece evidente que é justamente no contexto da organização escolar que as inovações educacionais podem implantar-se e desenvolver-se. Num certo sentido, não se trata tanto de inovar, mas de criar as condições organizacionais para que a inovação aconteça, para que as experiências pedagógicas não sejam sistematicamente destruídas com argumentos burocráticos, para que os profissionais do ensino se sintam motivados e gratificados por participarem em dinâmicas de mudança. (Nóvoa, 1992, p. 40-41)

É possível destacar três pontos a partir dessa colocação do autor no contexto de sua obra. Em primeiro lugar, percebe-se que a tradição da prática de inovação esteve sempre associada, até então, à necessidade de mudança de aspectos da educação 
condicionados por fatores determinantes externos à organização da vida escolar. Em segundo lugar, a participação dos professores no processo de mudança era algo imposto justamente por vir de fora da escola, de forma prescritiva e normativa. E, em terceiro lugar, percebe-se que as políticas educacionais elaboradas no nível hierárquico dos sistemas educacionais chegavam às escolas com os respectivos elementos instrumentais de administração, controle e avaliação, configurandose como um sufocante aparato burocrático de administração escolar repleto de prescrições, ao molde da teoria clássica da administração. Por fim, poderia se entender, a partir das ponderações de Nóvoa, que existiria uma factível apropriação "por dentro" da noção de inovação, a qual começaria a se afastar daquela noção preconizada por Huberman (1973).

Colocada dessa forma, a dinâmica da inovação dependeria dos aspectos de gestão da unidade escolar, no exercício da sua autonomia pedagógicoadministrativa que é sempre relativa, conforme pondera Barroso (2011), pois há sempre leis, normas e demais elementos da legislação a serem observados. Caberia, assim, à equipe de gestão e aos professores o desafio de proporcionar um ambiente favorável ao fomento de inovações na escola. Isso significa compreender que inovações de natureza didático-pedagógica podem ser articuladas a novas le inovadoras) formas de gestão escolar.

Percebe-se, dessa forma, a relevância assumida pela capacidade de a escola ativar processualmente a autonomia ao longo da construção do seu projeto políticopedagógico, o qual pode ser portador de inovações efetivas do ponto de vista do alcance político da formação humana plena, crítica e emancipatória, neutralizando ao menos em parte os determinantes externos e alheios às funções da escola como espaço privilegiado da formação cultural (Bildung), que em muito extrapolam as demandas de orientação estritamente econômica. Conforme argumenta Gruschka (2008), além do processo global que subsume a educação à economia, haveria uma deformação interna da formação como conteúdo e processo. Dito de outra forma, a razão instrumental (a "cultura industrial") migrou da esfera do mercado e instalou-se na própria educação. Como explica Gruschka (2008, p. 175), “[t]anto no plano mais geral quanto na prática pedagógica diária da escola, trata-se do enfraquecimento da lógica própria e da autonomia da Formação e da Educação como ordenadores da cultura". Sendo assim, qualquer resistência a esta corrosão da lógica interna da formação precisa ser enfrentada a partir de dentro da escola, daí o argumento da centralidade que ocupa a construção e fortalecimento da autonomia escolar.

Vale frisar que tomo a acepção de "autonomia da escola" no mesmo sentido da abordagem de Barroso (2011), significando que a educação e o próprio espaço escolar são vistos como um campo de forças, no qual entram em embate e se 
confrontam distintas lógicas e interesses, além do exercício político das influências externas e internas lpolíticas, de gestão, profissionais, pedagógicas, entre outras). A autonomia precisa ser construída pela escola mediante a participação e a discussão democráticas, conduzidas pelos indivíduos. Isso implica não ser possível haver "autonomia da escola" sem o reconhecimento e legitimidade da "autonomia dos indivíduos" (Barroso, 2011). Se tomarmos a educação como eminentemente política, como coloca Adorno (1995) em seu texto "Educação para quê?", posto que a exigência da produção de uma consciência verdadeira é, de fato, uma exigência política, então, obrigatoriamente a política educacional e a gestão escolar são também políticas.

Tomando-se o caráter político da educação é preciso ressaltar que a inovação no campo educacional - seja na política educacional (macrossistema), seja na gestão escolar (microssistema), na organização curricular, nos métodos e técnicas de ensino, nos materiais instrucionais e tecnologia educacional, na relação professor-aluno ou na avaliação (Ferretti, 1995) - pode ser pensada e implantada em favor de duas tipologias antagônicas, ou seja, polarizadas, a saber, il a crítica assentada na concepção de educação democrática, com vistas à qualidade social (e não à qualidade total ou empresarial), que mira a formação humana plena ou ii) a instrumental - baseada na concepção educacional tecnicista, na qual a educação fica submetida à lógica e aos interesses imediatistas do mercado. Isso, por seu turno, implica incluir a distinção também quanto ao fenômeno da inovação entre essas duas tipologias antagônicas na esfera da política e gestão educacional. Esta construção polarizada pode ser encontrada, de modo análogo, em Sander (2005) e Veiga (2010).

Sander (2005) aborda a existência de duas tendências em embate na elaboração, nas práticas e na produção de conhecimento de políticas públicas e gestão da educação no Brasil, a saber, o que ele nomeia de "gestão produtiva", a qual seria orientada ao mercado (viés econômico), e a "gestão democrática", voltada à formação cidadã e com orientação política e cultural (viés crítico). Veiga (2010) emprega os termos “educação estratégico-empresarial” e “educação emancipatória" para nomear as mesmas tipologias e evidenciar as distintas concepções norteadoras da construção do projeto político-pedagógico que emanam da esfera da política educacional, portanto, dos concorrentes projetos ideológicos em enfrentamento na sociedade que tentam se legitimar e concretizar como política educacional de facto e como ações e instrumentos de administração de sistemas e unidades escolares oficiais.

0 princípio constitucional e também presente na LDB da gestão democrática, que exige a condição de a escola estar aberta à participação dos atores sociais no seu espaço, os princípios da liberdade e os ideais de solidariedade humana, 
articulados à autonomia da escola, seriam os pilares de sustentação da educação cidadã, democrática e emancipatória, conforme argumenta Veiga (2010). Sobre esses pilares se constroem suas demais características. Uma educação emancipatória seria essencialmente inclusiva, acolhedora, orientada à formação plena e cidadã dos alunos, incluindo a formação para o trabalho como prática social, preocupada em atingir o desafio da oferta de educação de qualidade em que, particularmente, a ciência e a técnica sejam compreendidas como sistematizações de construção e reconstrução do conhecimento produzido e acumulado pelo homem historicamente.

Em embate com esta visão tem-se a concepção de "educação estratégicoempresarial", ou seja, uma educação instrumentalizadora. O utilitarismo, o pragmatismo e o imediatismo das concepções educacionais orientadas pela razão instrumental são marcas emblemáticas do posicionamento político economicista da função social da educação, ou seja, da visão funcionalista da escola em termos de seu papel na sociedade administrada. Na obra Eclipse da Razão, Horkheimer (2007, p. 55) assevera que o pragmatismo (filosófico) é o correlato do industrialismo moderno, "para quem a fábrica é o protótipo da existência humana, e que modela todos os ramos da cultura segundo a produção em linha de montagem ou segundo o escritório executivo racionalizado". É devido a isso que ele desvela que todo pensamento, para ser concebido, deve estar assentado em um álibi, o registro de sua utilidade. Na educação - particularmente na política educacional - essa crítica imamente à racionalidade do funcionamento da sociedade administrada permite compreender o discurso legitimador da necessidade de perene mudança da educação para atender às necessidades de formação requisitadas pelo setor produtivo e para conseguir adentrar (e permanecer) no mercado de trabalho, ou seja, as habilidades cognitivas, as atitudes e comportamentos psicológicos lque atestariam a "empregabilidade") e as competências profissionais estritamente aderentes à lógica econômica, ou seja, ao escrutínio da competitividade.

Pode-se localizar idêntica distinção tipológica conduzida por Veiga (2003) sobre o papel da inovação na educação. Assim, a autora nomeia a concepção de inovação instrumental por "inovação regulatória ou técnica" e sua oposta de "inovação emancipatória ou edificante".

$\mathrm{Na}$ sua perspectiva de inovação emancipatória "os processos inovadores lutam contra as formas instituídas e os mecanismos de poder. É um processo de dentro para fora" (Veiga, 2003, p.274). Verifica-se, assim, uma franca oposição à noção de inovação de Huberman (1973). Ainda segundo Veiga (2003), a inovação apresenta natureza ético-social e cognitivo-instrumental, visando à eficácia dos processos formativos, os quais, por seu turno, se dão pelo crivo da exigência ética e não sob a égide da razão instrumental que anima a "inovação regulatória ou técnica". 
Segundo a autora, a inovação regulatória ou técnica, típica da esfera empresarial - e, portanto, estranha ao campo educacional -, exclui do seu processo de elaboração o próprio agente inovador, que não é inclusive afetado por ela, a não ser como mero assimilador, portanto, como objeto. Isso se dá pela intrínseca separação entre meios e fins e entre "estrategistas" lque concebem, projetam, modelam) e "executores" (que cumprem papéis em suas respectivas funções gerenciais). Essa dupla separação acaba por escamotear eventuais conflitos e silenciar possíveis definições e/ou soluções alternativas. Dessa forma, impedese o trabalho coletivo e democrático necessário à construção de um projeto educacional efetivamente inovador do ponto de vista emancipatório, posto que os reais sujeitos que trabalham no cotidiano escolar ficam submetidos a atuar como participantes de uma inovação "imposta" por instâncias hierárquicas superiores (Ministério da Educação, secretarias de educação estaduais e/ou municipais, diretorias de ensino etc). Verifica-se, adicionalmente, o viés sistêmico da visão de administração educacional inerente a essa concepção de inovação, além da divisão social do trabalho no campo da educação.

A lógica da administração empresarial invadiu historicamente o campo da educação (Sander, 2007) e não seria diferente com o processo de gestão da inovação educacional - interferindo diretamente nas questões pedagógicas -, que fica, assim, sob a tutela da mesma racionalidade instrumental orientada economicamente, a qual preside a administração e a forma de gerência capitalista. Isso fica claro na análise de Veiga (2003, p. 269):

Os processos inovadores continuam a orientar-se por preocupações de padronização, de uniformidade, de controle burocrático, de planejamento centralizado. Se a inovação é instituída, há fortes riscos de que seja absorvida pelas lógicas preexistentes, pelos quadros de referência reguladores.

Entendida pela lógica de mercado, a inovação regulatória ou técnica é concebida e aplicada de modo "cientificamente" planejado e controlado, gerencialmente. Nesses termos, esta tipologia é um fenômeno de fora para dentro, no qual a relação do "novo" com o "existente" pode se configurar como mudança, rearticulação ou reforma a serviço do sistema social à qual a escola estaria subordinada em termos de seu papel esperado. Segundo Veiga (2003, p. 270), “inovar é, portanto, introduzir algo diferente dentro do sistema para produzir uma mudança organizacional descontextualizada".

Tal mudança não produz um projeto pedagógico novo, ela reproduz o mesmo sistema, porém modificado. Trata-se de uma mudança conservadora. Sua marca é não levar em consideração as diferenças entre os sujeitos, as forças sociais 
locais da escola e os anseios dos atores sociais envolvidos. De modo sintético, essa inovação educacional subsumida estritamente à dimensão do econômico e dos valores de mercado é coordenada pela perspectiva do tecnicismo pedagógico, do behaviorismo psicológico e do positivismo científico. Esses seriam os "ingredientes" a fundirem-se em seu cadinho, amalgamando-se finalmente nos planos de reforma sistêmicos, nas estratégias de mudança cultural e administrativa - os "choques de gestão" ${ }^{4}$ para mudar a cultura organizacional das instituições escolares -, nas propostas salvacionistas que têm nos recursos tecnológicos, especialmente no computador e nos sistemas de informação, a "mola" para dar o salto para a dita “revolução" na educação.

No outro polo, a noção de "inovação emancipatória ou edificante" apresentada por Veiga (2003) parte de outra base epistemológica, não podendo estar associada à administração empresarial e ao controle de tipo gerencial capitalista. Devido a isso, a inovação emancipatória não pode ser entendida como sinônimo de evolução, reforma ou mudança conservadora nos seus sentidos intrínsecos à racionalidade instrumental. Ao contrário, a inovação é tomada como uma produção humana, inegavelmente atrelada à realidade histórica e social.

De modo bastante distinto da tipologia anteriormente abordada, a inovação emancipatória ou edificante tem seus processos inovativos como ações de luta contra formas instituídas (existentes) e com os mecanismos de poder. Isso configura essa tipologia de inovação como um processo de dentro para fora. Deve-se lembrar, no entanto, que só é possível haver tal tipo de inovação em ambientes escolares com autonomia construída pelos seus atores, o que depende do exercício da autonomia intelectual desses indivíduos. Veiga (2003) traz à tona as três dimensões que configurariam, do seu ponto de vista, a finalidade da educação ao se tratar de inovação e sua relação com o projeto político-pedagógico:

Falar em inovação e projeto político-pedagógico tem sentido se não esquecermos qual é a preocupação fundamental que enfrenta o sistema educativo: melhorar a qualidade da educação pública para que todos aprendam mais e melhor. Essa preocupação se expressa muito bem na tríplice finalidade da educação em função da pessoa, da cidadania e do trabalho. (Veiga, 2003, p. 268)

As três finalidades apontadas pela autora estão associadas às seguintes dimensões do processo formativo: a subjetividade (pessoa), a política (cidadania)

4. “As Instituiç̃̃es de Educação Superior precisam de um choque de gestão para que melhor possam cumprir sua missão de forma eficiente e eficaz. [...] Além disso, os mecanismos internos, administrativos ou acadêmicos precisam ser revistos." (CNI, 2004, p. 30, grifo meu) 
e o trabalho. De fato, são categorias quando pensadas em seu sentido históricosocial enquanto funções e ao mesmo tempo finalidades da educação. Tomo-as emprestadas de Ilma Veiga para iniciar, na próxima seção, a trajetória de pensar a inovação educacional a partir da constelação teórico-metodológica da Teoria Crítica, particularmente empregando as contribuições de Theodor Adorno. Nomeio de trajetória, pois a intenção desse ensaio é enunciar quais seriam as condições do a apriori de tal abordagem, a qual poderia nomear inovação educacional críticoemancipatória.

\section{Teoria crítica da inovação em educação}

É preciso partir do ponto fundamental que toda ação inovadora, como ato humano, é necessariamente intencional, carregando finalidades valorativas e, portanto, é política. Isso requer o resgate da compreensão da formação cultural (Bildung) e também de sua acepção deformada pela indústria cultural na sociedade administrada do capitalismo contemporâneo, ou seja, aquilo que Adorno (2010) chamou de semiformação (Halbbildung). Qualquer ação ou proposta que preconize uma inovação educacional no sentido de proporcionar aos alunos uma formação crítica e emancipatória se chocará - antes de tudo - com o próprio obstáculo da cultura existente, ou seja, é preciso pôr em relevo o fato de que o pressuposto da emancipação como condição para uma sociedade livre encontra-se diante da dificuldade objetiva primeira da ausência de liberdade nessa sociedade (Adorno, 1995). Devido a isso é necessário compreender a educação como fenômeno social e político. 0 primeiro compromisso político dessa concepção de educação seria estimular o comportamento crítico, tendo como orientação a emancipação no sentido adorniano, ou seja, o processo perene de realização da autorreflexão crítica, de construção da autonomia intelectual derivada da compreensão de Kant 1985, p. 100) - a noção de Mündigkeit, o “servir-se de si mesmo sem a direção de outrem”, a libertação da necessidade de tutela, fazendo uso do próprio entendimento luso da razão) - mirando-se a "produção de uma consciência verdadeira" (Adorno, 1995, p. 141). Não se trata de pontos de chegada, de metas idealizadas, mas de um devir, de um vir-a-ser que passa, necessariamente, por tornar todas as contradições dessa sociedade - particularmente das funções da educação, da ciência e da tecnologia claras e conscientes nas ações educativas. Como argumenta o intelectual alemão, “pensar é, já em si, antes de todo e qualquer conteúdo particular, negar, é resistir ao que the é imposto [...]". (Adorno, 2009, p. 25)

Vale esclarecer, como faz Gomes (2010, p. 204), que a educação emancipatória não se sustenta pela mera retórica; ao contrário, está assentada na “crítica das 
condições objetivas que promovem a semiformação". Pode-se encontrar no texto "Educação - para quê?" a relação entre pensamento e produção da consciência verdadeira:

[...] aquilo que caracteriza propriamente a consciência é o pensar em relação à realidade, ao conteúdo - a relação entre as formas e estruturas de pensamento do sujeito e aquilo que este não é. Este sentido mais profundo de consciência ou faculdade de pensar não é apenas o desenvolvimento lógico formal, mas ele corresponde literalmente à capacidade de fazer experiências. Eu diria que pensar é o mesmo que fazer experiências intelectuais. Nesta medida e nos termos que procuramos expor, a educação para a experiência é idêntica à educação para a emancipação. (Adorno, 1995, p. 151)

Desse excerto também se pode tomar a questão da subjetividade la categoria relacionada à "pessoa") e uma possibilidade de sua leitura à luz da obra de Adorno. É preciso esclarecer que, quando se preconiza a emancipação do indivíduo, não se trata de ter a pretensão de cultivar indivíduos ao modo idealista (e ingênuo) ou de modelar pessoas. A individuação discutida por Adorno (1995) vai na direção de resgatar a importância da capacidade de o indivíduo realizar experiências formativas, as quais não se dão na relação formal do conhecimento com o educando e sem a mediação deste com os objetos na e da realidade concreta, mas exatamente o oposto disso. Como coloca Wolfgang Leo Maar, “o modelo da experiência formativa é a dialética do trabalho social" (Adorno, 1995, p. 25). Há, adicionalmente, que se respeitar os tempos dos indivíduos na atividade pedagógica para poderem refletir sobre os objetos do conhecimento, pois disso depende qualquer inovação educacional que se pretenda crítico-emancipatória e que busque a superação da imediatidade, da fragmentação do saber, da cega instrumentalização estéril, da volúpia da mudança pela mudança.

A categoria trabalho carrega consigo a tensão dialética posta por Adorno na Dialética Negativa e nos debates radiofônicos com Helmut Becker, na década de 1960, mais precisamente no texto "Educação e emancipação". Refiro-me à tensão entre os momentos da adaptação (do indivíduo à sociedade, de modo geral, e às necessidades econômicas e do mercado de trabalho, de modo específicol e da emancipação. Essa polarização também se faz presente entre a heteronomia, que se impõe aos indivíduos de modo brutal (na necessidade de autoconservação), e a autonomia. E, de modo análogo, se poderia apontar a tensão entre a educação como estrito ajustamento social e como formação para o mercado de trabalho (adestramento, treinamento, qualificação, capacitação) e a educação como formação cultural (Bildung), ou seja, que tenha em seu horizonte a autorreflexão 
crítica, o sentido pleno da educação, conforme discute Adorno (1995) no texto “Educação após Auschwitz".

Qualquer posição tomada univocamente direcionada a um desses polos se configuraria, identicamente, como semiformação. 0 desafio estaria em oferecer uma educação capaz de possibilitar aos indivíduos que se orientem no mundo ${ }^{5}$ para viver e trabalhar, mas que não fiquem apenas nisso, produzindo nada além de "pessoas bem ajustadas" (Adorno, 1995, p. 143). Quando se toma a categoria trabalho para além da produção de valor de troca, então, a educação para o trabalho passa a incorporar os elementos do plano cultural e político, perfazendo a necessária mediação dialética e culminando na acepção de trabalho social. As inovações educacionais crítico-emancipatórias poderiam residir nas políticas e nas ações de gestão democráticas da educação capazes de resgatar a aptidão à experiência formativa nos alunos. É por meio delas que se frutificaria o potencial emancipatório orientado à formação da consciência. Isso exige resistência e negação do existente, dificílimas de enfrentar e, como alerta Adorno,

Justamente quando é grande a ânsia de transformar, a repressão se torna muito fácil; [e] as tentativas de transformar efetivamente o nosso mundo em um aspecto específico qualquer imediatamente são submetidas à potência avassaladora do existente e parecem condenadas à impotência. (Adorno, 1995, p. 185)

Colocar tudo isso sob o holofote esclarecedor do pensamento rigoroso e realizar a crítica imanente das estruturas de poder que atravessam a sociedade pode ser um gérmen de inovações crítico-emancipatórias na educação.

\section{Considerações finais}

Procurei, neste ensaio, apresentar duas tipologias antagônicas que se colocam na arena da política educacional com óbvias implicações derivadas para a gestão educacional e as hipotéticas formas de inovação em educação a elas associadas. Apesar de se terem apontadas algumas inovações recentemente concretizadas na política do ensino médio, as análises feitas podem ter validade para as demais modalidades e níveis de ensino. Isso porque, quando se acirra a concorrência empresarial, a lógica da competitividade mercantil traz à tona o discurso

5. Adorno emprega a expressão "necessidade de se orientar no mundo" para se referir ao momento de adaptação do processo formativo, ou seja, a preparação para trabalhar e sobreviver na sociedade existente, na qual imperam as forças econômicas de mercado. (Adorno, 1995, 2008) 
pretensamente legitimador da inovação tecnológica como fator determinante do "sucesso" também para o lócus do conhecimento. Seja a escola ldesde a educação básica até o nível superior), vista como local para formar os egressos capazes de "empregabilidade" na chamada "sociedade do conhecimento", seja a universidade como produtora de pesquisa aplicada, é a figura do empreendedor e seu ethos racional-instrumental que passam a inspirar as reformas inovadoras para promover a revolução advogada pelo setor produtivo.

A educação, de modo particular, se apresenta vulnerável porque é na arena da política educacional que se definem os fins aos quais serviria. Há uma nítida polarização de valores em embate, tendo-se o mercado como porta-voz da defesa do ponto de vista da educação como instrumento de qualificação profissional, adaptação do indivíduo às suas necessidades (cognitivas, comportamentais e laborais) e de seu ajustamento à sociedade, principalmente ao estilo de vida do consumismo. E, no outro polo, o entendimento da educação como fenômeno cultural, social e eminentemente político, cuja finalidade é a plena formação humana - da pessoa - em suas múltiplas dimensões (cultural, política, emocional-subjetiva e para o trabalhol.

Uma factível noção crítica de inovação em educação teria como pedra angular a tomada de posição política inicial da formação para o enfrentamento consciente da "regressão da cultura" diante da pressão exercida pela indústria cultural e como produto da semiformação. Resistir, a partir do estímulo pedagógico ao pensamento crítico, rigoroso e autônomo seria negar o existente posto como indissolúvel nessa sociedade administrada e rejeitar o conformismo. Sendo assim, propostas de inovações educacionais - por esta outra base epistemológica, distinta da oriunda na ciência econômica e na administração empresarial poderiam se mostrar como possibilidades de ruptura com a razão instrumental e a passividade intelectual e, adicionalmente, de transformação da escola em lócus de fomento da experiência formativa, em termos adornianos. Retomando a ideia seminal de Andréas Gruschka, seria primordial que essa plausível dinâmica inovadora crítico-emancipatória surgisse de dentro da escola - tendo como protagonistas professores, profissionais da educação e comunidade escolar. Seria, assim, necessário que fosse um movimento intrínseco à realidade e à cultura escolares, pois a partir desse núcleo interno se poderia buscar a consolidação da autonomia pedagógico-administrativa imprescindível ao resgate da função social original de ordenadoras da cultura que cabem à formação e à educação. 


\section{Referências}

ADORNO, Theodor Wiesengrund. Educação e emancipação. São Paulo: Paz e Terra, 1995. . Introdução à sociologia. São Paulo: Editora UNESP, 2008. . Dialética negativa. Rio de Janeiro: Jorge Zahar Editor, 2009. . Teoria da semiformação. In: PUCCI, Bruno; ZUIN, Antônio Soares; LASTÓRIA, Luiz

A. Calmon Nabuco (Org.). Teoria crítica e inconformismo: novas perspectivas de pesquisa. Campinas, SP: Autores Associados, 2010.

BARROSO, João. O reforço da autonomia das escolas e a flexibilização da gestão escolar em Portugal. In: FERREIRA, Naura Syria Carapeto (Org.). Gestão democrática da educação: atuais tendências, novos desafios. 7 ed. São Paulo: Cortez, 2011.

BRASIL. Ministério da Ciência e Tecnologia (MCT), Centro de Gestão de Estudos Estratégicos (CGEE). Livro azul da 4a Conferência Nacional de Ciência, Tecnologia e Inovação para o desenvolvimento sustentável. Brasília, DF: Ministério da Ciência e Tecnologia, 2010a.

. Sessão plenária 4: Educação e C,T\&I - educação de qualidade desde a primeira infância. Brasília, DF: Ministério da Ciência e Tecnologia, $2010 b$.

BRASIL. Ministério da Educação (MEC), Conselho Nacional de Educação (CNE), Câmara de Educação Básica (CEB). Resolução no 2, de 30 de janeiro de 2002. Define Diretrizes Curriculares Nacionais para o Ensino Médio. Diário Oficial da União, Brasília, DF: 31 jan. 2012a. Seção 1, p. 20.

. Parecer no 5, de 04 de maio de 2011. Sobre as Diretrizes Curriculares Nacionais para o Ensino Médio. Diário Oficial da União, Brasília, DF: 24 jan. 2012b. Seção 1, p. 10. BRASIL. Ministério da Educação (MEC), Secretaria de Educação Básica, Diretoria de Concepções e Orientações Curriculares para a Educação Básica, Coordenação Geral de Ensino Médio. Ensino Médio Inovador. Brasília, DF: Ministério da Educação, 2009. Disponível em: < http://portal.mec.gov.br/dmdocuments/ensino_medioinovador.pdf>. Acesso em: 04 fev. 2013.

CONFEDERAÇÃO NACIONAL DA INDÚSTRIA - CNI (Brasil). Mapa estratégico da indústria: 2007-2015. Brasília: CNI, 2005.

. Contribuição da indústria para a reforma da educação superior. Brasília: CNI/ SESI/SENAI/IEL, 2004.

CUNHA, Luís Antônio. Educação, estado e democracia no Brasil. 6 ed. São Paulo: Cortez; Niterói, RJ: Editora da UFF; Brasília, DF: FLACSO do Brasil, 2009.

DIAS, Rafael de Brito. O que é a política científica e tecnológica. Sociologias, Porto Alegre, ano 13, n. 28, set./dez. 2011.

FERRETTI, Celso João. A inovação na perspectiva pedagógica. In: GARCIA, Walter E. (Coord.). Inovação educacional no Brasil: problemas e perspectivas. 3 ed. Campinas, SP: Autores Associados, 1995. 
GOMES, Luiz Roberto. Teoria crítica, educação e política. In: PUCCI, Bruno; ZUIN, Antônio Soares; LASTÓRIA, Luiz A. Calmon Nabuco (Org.). Teoria crítica e inconformismo: novas perspectivas de pesquisa. Campinas, SP: Autores Associados, 2010.

GRUSCHKA, Andréas. Escola, didática e indústria cultural. In: DURÃO, Fabio Akcelrud; ZUIN, Antônio; VAZ, Alexandre Fernandez (Org.). A indústria cultural hoje. São Paulo: Boitempo, 2008.

HORKHEIMER, Max. Eclipse da razão. 7 ed. São Paulo: Centauro, 2007.

HUBERMAN, Alan Michael. Como se realizam as mudanças em educação: subsídios para o estudo do problema da inovação. São Paulo: Cultrix, 1973.

KANT, Immanuel. Textos seletos: edição bilíngue. 2 ed. Petrópolis, RJ: Vozes, 1985.

MOTOYAMA, Shozo. Os principais marcos históricos em ciência e tecnologia no Brasil. Revista da Sociedade Brasileira de História da Ciência, n. 1, 1985.

NÓVOA, António. (Coord.). As organizações escolares em análise. Lisboa: Dom Quixote, 1992.

ROSENBERG, Nathan. Por dentro da caixa-preta: tecnologia e economia. Campinas, SP: Editora da Unicamp, 2006.

SANDER, Benno. Administração da educação no Brasil: genealogia do conhecimento. Brasília, DF: Líber Livro, 2007.

Políticas públicas e gestão democrática da educação. Brasília, DF: Líber Livro, 2005.

TÜRCKE, Christoph. Sociedade excitada: filosofia da sensação. Campinas, SP: Editora da Unicamp, 2010.

VEIGA, IIma Passos Alencastro. Projeto político-pedagógico: novas trilhas para a escola. In: VEIGA, IIma Passos Alencastro; FONSECA, Marília. (Org.). As dimensões do projeto político-pedagógico. 8 ed. Campinas, SP: Papirus, 2010. . Inovações e projeto político-pedagógico: uma relação regulatória ou emancipatória? Cadernos Cedes, Campinas, v. 23, n. 61, pp. 267-281, dez. 2003.

Recebido em fevereiro de 2015

Aprovado em maio 2015

Darlan Marcelo Delgado é pós-doutorando em Educação no Departamento de Educação (DEd) da Universidade Federal de São Carlos (UFSCar) e docente do Centro Estadual de Educação Tecnológica Paula Souza (CEETEPS). E-mail: darlandelgadolaterra.com.br 